\title{
Erratum to: Origins of Life and Evolution of Biospheres
}

\section{A. J. MacDermott}

Published online: 7 November 2009

(C) Springer Science + Business Media B.V. 2009

\section{Erratum to: Orig Life Evol Biosph}

In the previous issue, the three papers by MacDermott et al. appeared in incorrect order.

The correct sequence should be:

Evaluation of Coupled Perturbed and Density Functional Methods of Computing the ParityViolating Energy Difference between Enantiomers

Electroweak Parity-Violating Energy Shifts of Amino Acids: The "Conformation Problem"

Parity-Violating Energy Shifts of Murchison L-Amino Acids are Consistent with an Electroweak Origin of Meteorite L-Enantiomeric Excesses

\footnotetext{
A. J. MacDermott $(\bowtie)$

Department of Chemistry, School of Science, Computing and Engineering,

University of Houston-Clear Lake, 2700 Bay Area Boulevard, Houston, TX 77058-1098, USA

e-mail: macdermott@uhcl.edu
} 